\title{
Ultrasound of the Neck
}

National Cancer Institute

\section{Source}

National Cancer Institute. Ultrasound of the Neck. NCI Thesaurus. Code C137925.

An ultrasound of the neck. 